\title{
CONSECUTIVE BITES ON TWO PERSONS BY SAME KRAIT SNAKE: TWO FATAL CASE SERIES WITH TRADITIONAL TREATMENT
}

\author{
DR. RATINDRA NATH MONDAL ${ }^{1}$, DR. MONI RANI GUPTA², DR MD ROBED AMIN ${ }^{3}$
}

\begin{abstract}
:
Snakebite is one of the leading causes of unnatural death in Bangladesh. Incidence of snake bite is common in rural areas. Commonly single event of interaction with snake with affected individual are observed. Venomous snake usually does not exhaust its venom for prey. Events with consecutive bites on different people have been observed worldwide including Bangladesh. Two events of consecutive bites on two people by a single snake was observed in last year in Bangladesh. One event occurred in Chadpur and another in Chuadhanga. In both incidences all the 4 victims were sleeping and bitten consecutively by snake. Unfortunately all the victims of this case series died. The victims died due to people's ignorance about the modern management of snake bite and unavailability of antisnake venom.
\end{abstract}

\section{Introduction}

Snake bite is the single most important cause of envenoming worldwide and results in substantial mortality in many parts of Africa, Asia, and the Americas ${ }^{1}$. Snake bite is significantly neglected as a public health problem in the world as evidenced by the lack of available incidence data from most of the rural tropics where snake bites occurs frequently ${ }^{2}$. Recent estimates, which are fragmentary, variously suggest that worldwide, venomous snakes cause " 5.4 million bites, about 2.5 million envenomings and over 125,000 deaths annually"3. More recently Anuradhani et al reported that, globally at least 421,000 envenomings occur annually, but this may be as high as $1,841,000^{4}$. According to this estimate, the highest numbers of envenomings are estimated for South Asia $(121,000)$ followed by South East Asia $(111,000)$, and East Sub-Saharan Africa (43000).

The true incidence of snake bite in rural Bangladesh is largely unknown. Previously, an incidence of 4.3 snake bites per 100,000 populations was reported with approximately 2000 deaths occurring annually in Bangladesh ${ }^{5}$. This estimate is based on data from a small study. During 1988-89, a small survey was conducted in 50 Upazillas (sub-districts) of Bangladesh that recorded 764 episodes of snakebite, of which $168(22 \%)$ died $^{6}$. Snake bite particularly in the rural tropics is a major cause of mortality and morbidity, and it has a significant impact on human health and economy through treatment related expenditure and loss of productivity ${ }^{7}$.
Snake bite is a result of an unfortunate accidental interaction between a snake and a human victim. Most often the victim is an active poor young people who get the bite during day to day occupational activity like cultivation, fishing, plantation, wood collection, watching the 'crop' or 'garden' lying in floor or even during rural foot walk. Sometimes it happens in home surrounding like while on chicken or pet bird care ${ }^{8}$. Most snakebite victims are young. ${ }^{9}$. The major venomous snakes of Bangladesh are cobras, kraits, green pit vipers and sea snakes in coastal areas. Green pit vipers of the genera trimeresurus (popularly known as Gaaltawa) are available in forested areas of the country like greater Chittagong, and Sylhet areas. ${ }^{10}$

Due to huge population is on activity and the dwellings of snakes are also areas where people used to work there is chances of more interaction with snakes and chances of multiple bite can be seen. There has been report of consecutive bites on activity in Bangladesh. Those case series observed consecutive interaction with suspected cobra bite but timely approach to a well equipped snake bite study clinic in Chittagong Medical College Hospital(CMCH) leads to a complete recovery in all 4 victims. Here is a series of unfortunate events of consecutive bites in different people with fatality in rural setting with poor background of snake bite management in Bangladesh

\section{Case report 1:}

The first case occurred in Polli Hosenpur village, union Nagdhao, upazilla Alamdhanga, dist.

1. Assistant professor of Medicine, Rangpur Community Medical College

2. Honorary Medical officer of Medicine, $\mathrm{RpMCH}$

3. Associate Prof of Medicine, Dhaka Medical College

Bangladesh J Medicine 2013; 24 : 31-34 
Chuadhangaon $26^{\text {th }}$ September at 3.00 AM. Victims were Mr. J. I (35) and her daughter Sr (10 month). As it was a hot humid day Mr. J was sleeping at the floor of his yard along with his son, daughter and wife. At 3 AM he wakes up due to pain in his foot. He thought that he was bitten by an insect (Chua). He called his wife and switch on the light and saw a snake on the corner of the bed. After that Mr. J killed the snake himself. At 3.30 AM local ojha started to treat him with some meaningless traditional treatment.

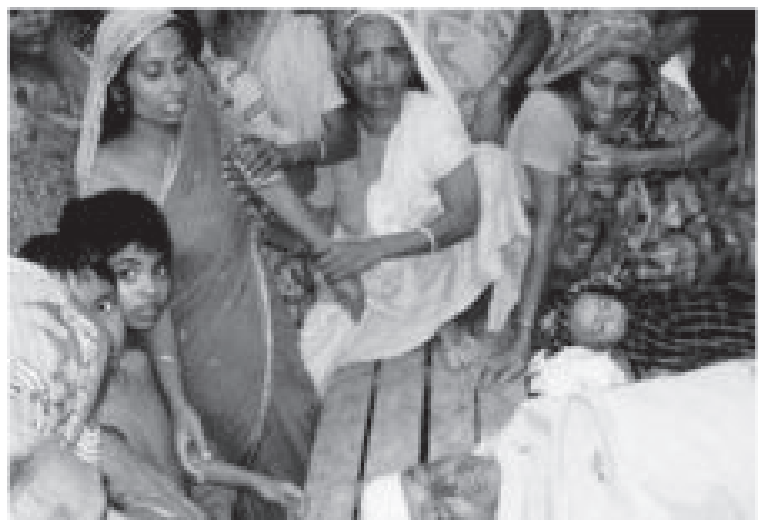

At $5 \mathrm{AM}$ as his condition deteriorate he was taken to Chuadhanga Sador hospital. There he was treated with polyvalent anti venom (7vials), but he died at 8 AM. His daughter was also bitten by the snake but no one noticed this. At about 6 AM Sr developed restlessness and excessive salivation, then her family members suspected she was also bitten by the snake and she was taken to the same hospital. There was no more antivenom available at that time, they referred her to Rajshahi Medical College Hospital and she died at 8.30 AM. The local people identified the snake as black old snake (Kalo bura sap), the local name of krait snake.

\begin{tabular}{lll}
\hline & Mr. Johurul Islam & Sriti \\
\hline Age & 35 years & 10 months \\
Snake bite (probably) & Second time & First \\
First aid & By Ojha & By Ojha \\
Main treatment & By Ojha and & By Ojha and \\
& hospitalization & hospitalization \\
Antisnake venom & Given 7 vials & Not given \\
Death occurred & Earlier & later \\
\hline
\end{tabular}

\section{Case report 2:}

The second case occurred in Cot chadpur at $25^{\text {th }}$ July, 2011. Newly married couple N.D (20years) and S. R. D (18years) was inhabitants of Bagdhanga village of Cot chadpur upazilla. On $25^{\text {th }}$ July Monday at night after taking their dinner they slept at their bed. At mid night $\mathrm{S}$. $\mathrm{R}$ wake up and shouted that something was bitten her feet. Then her husband switched on light and found a snake biting his wife's foot. He tried to remove the snake but unfortunately he was also bitten by the snake. After that both of them feel sick and they were treated by Ojha with traditional methods (jhar-fuk). On $26^{\text {th }}$ July, S.R. D died at 5.00 AM. She was not taken to hospital.

N .D was taken to Cot chadpur thana health complex after his wife's death. At the hospital there was no antivenom and the patient was referred to higher center, but as the patient was poor they returned the patient back to home at $8.00 \mathrm{AM}$ and continued treatment by Ojha and he died at 8.30 AM, without getting any modern treatment (antivenom) even after hospitalization.

\begin{tabular}{lll}
\hline & Nobokumar Das & Shanti Rani Das \\
\hline Age & 20 years & 18 years \\
Snake bite & Second time & First \\
First aid & By Ojha & By Ojha \\
Main treatment & $\begin{array}{l}\text { By Ojha and } \\
\text { hospitalization }\end{array}$ & By Ojha \\
Antisnake venom & Not given & Not given \\
Death occurred & Later & Earlier \\
\hline
\end{tabular}

We have collected the photo of the snake and send it to Snake species expert for identification of the species, he identified that the snake was a Bungarus caeruleus (common krait).

\section{Discussion:}

Successive venomous bites on two boys by a single snake, resulting in almost fatal envenomation, were first reported in Bangladesh, by the Snake bite study clicin(SBSC), in $\mathrm{CMCH}$, on $1999 .{ }^{11} \mathrm{~A}$ similar event, reported in another study, which involved two brothers, was also registered in the same hospital. The latter accident happened during the day ${ }^{12}$, differently from the first report, in which the bites occurred at home while the two boys were sleeping. It has been reported that cobra strikes are more ineffective during the day; on the other hand, they are more dangerous at night, when snake eyesight is more acute ${ }^{13}$. This current report is the first reported consecutive bite caused by Bungarus caeruleus (common krait) in Bangladesh.

In view of the high proportion of bites, by some venomous species that results in little or no envenomation, it was suggested that snakes may be capable of biting defensively without injecting venom. Some viperidae species can inject up to ten lethal doses of venom (to their natural prey) in consecutive strikes 14,15 . The quantity of venom injected in each 
strike appears to be very variable and the popular belief that snakes are less dangerous after feed is not true $14,15,16$. These reptiles do not exhaust their store of venom, even after several strikes, and do not become less venomous after eating their prey ${ }^{15}$, 16 .

Kraits are ophiophagous, preying primarily upon other snakes (including venomous varieties) and are cannibalistic, feeding on other kraits. They will also eat mice and small lizards. ${ }^{17}$ All kraits are nocturnal. They are more docile during the daylight hours; at night they become very active, but are not very aggressive even when provoked. They are actually rather timid, and will often hide their heads within their coiled bodies for protection. When in this posture, they will sometimes whip their tail around as a type of distraction. ${ }^{18}$ Often in rainy season the snakes come out of their hiding places and find refuge on dry places inside a house. If bitten by it in sleep the victim seldom comes to know as the bite feels more like an ant bite or a mosquito bite. The victim may be dead before he even wakes up. ${ }^{19}$

Bungarus species have highly potent neurotoxic venom which can induce muscle paralysis. Clinically, their venom contains mostly pre-synaptic neurotoxins. These affect the ability of neuron endings to properly release the chemical that sends the message to the next neuron. Following envenomation with bungarotoxins, transmitter release is initially blocked (leading to a brief paralysis), followed by a period of massive overexcitation (cramps, tremors, spasms), which finally tails off to paralysis. These phases may not be seen in all parts of the body at the same time. Since kraits are nocturnal they seldom encounter humans during daylight hours, so bites are rare and they may prefer to deliver non-fatal bites, ${ }^{20}$ but a bite from a krait is potentially life-threatening, and should be regarded as a medical emergency.

The effect of venomous bite result in development of local swelling, prolonged bleeding, hypotension, paralysis, skeletal muscle damage, renal failure, cardiac abnormalities. In the initial period following bite clinical distinction between venomous bite and non-venomous bite may not be possible with certainty when close observation will provide clues if there is any features of envenomation on specific system. Typically, victims start to complain later of severe abdominal cramps accompanied by progressive muscular paralysis, frequently starting with ptosis. As there are no local symptoms, a patient should be carefully observed for tell-tale signs of paralysis (e.g. the onset of ptosis, diplopia and dysphagia) and treated urgently with antivenom. There is frequently little or no pain at the site of a krait bite, which can provide false reassurance to the victim. The major medical difficulty of patients envenomated are the lack of medical resources (especially intubation supplies and mechanical ventilators in rural hospitals) and the ineffectiveness of the antivenom. Definitive care may also be delayed as patients may first visit the local mantrik or tantrik, a holy person and traditional healer who may attempt to rid the body of the venom with spells or herbal remedies, which are ineffective interventions.

Once at a healthcare facility support must be provided until the venom is metabolised and the victim can breathe unaided, especially if there is no speciesspecific antivenom available. Given that the toxins alter acetylcholine transmission which causes the paralysis, some patients have been successfully treated with cholinesterase inhibitors such as physostigmine or neostigmine, but success is variable and may be species dependent as well. If death occurs it typically takes place approximately 6 to 12 hours after the krait bite, but can be significantly delayed. Cause of death is usually respiratory failure i.e. suffocation via complete paralysis of the diaphragm. Even if patients make it to a hospital subsequent permanent coma and even brain death from hypoxia may occur given potentially long transport times to get medical care.

The mortality rates caused by the members of this genus vary among different species: Envenoming and deaths resulting from snakebites, however, are a particularly important public health problem in the rural tropics. Populations in these regions experience high morbidity and mortality because of poor access to health services, which are often suboptimal, and, in some instances, a scarcity of antivenom, which is the only specific treatment. A large number of victims survive with permanent physical sequelae due to local tissue necrosis and, no doubt, psychological sequelae.

\section{References:}

1. White J, Warrell D, Eddleston M, Currie BJ, Whyte IM (2003) Clinical Toxicology - where are we now? Clin Toxicol 41: 263-276. Find this article online

2. Swaroop S, Grab B (1954) Snakebite mortality in the world. Bulletin of the World Health Organization 10: 3576. Find this article online

3. Chippaux JP (1998) Snake-bites: appraisal of the global situation. Bull World Health Organ 76: 515-524. Find this article online

4. Kasturiratne A, Wickremasinghe AR, de Silva N, Gunawardena NK, Pathmeswaran A, et al. (2008) The global burden of snake bite: a literature analysis and modelling based on regional estimates of envenoming 
and deaths. PLoS Medicine 5: e218. Find this article online

5. Sarker MS, Sarker NJ, Patwary S (1999) Epidemiological survey of snake bite incidences in Bangladesh. J Biol Sci 8: 53-68. Find this article online

6. Huq F, Islam MA, Sarker MH, Chowdhury B, Ali MW, et al. (1995) Epidemiology of snake bite in Bangladesh. Bangladesh J Zool 23: 61-64. Find this article online

7. Faiz MA, Hossain MR, Younus A, Das EB, Karim JC, et al. (1995) A hospital based survey of snake bite in Chittagong Medical College. Journal of Bangladesh College of Physicians and Surgeons 13: 3-8. Find this article online

8. Daniel J C (1983). The book of Indian Reptiles. Bombay Natural History Society, Oxford University Press.

9. Hansdak SG, Lallar KS, Pokharel P, Shyangwa P, Karki $\mathrm{P}$, et al. (1998) A clinico-epidemiological study of snake bite in Nepal. Trop Doct 28: 223-22.

10. Daniel J C (1983). The book of Indian Reptiles. Bombay Natural History Society, Oxford University Press.

11. Mamun SMH., Faiz MA., Rahman R., Chowdhury FE., Wahab MA., Ataher QS. Two consecutive venomous bites by the same snake: a case report. Society of Medicine $1^{\text {st }}$ Conference, 2000.
12. Amin MR, Mamun SMH, Chowdhury NH, Rahman M , Ghose A ,Al Hasan A , Faiz MA : Consecutive Bites On Two Pesons By The Same Cobra: A Case Report. J. Venom. Anim. Toxins incl. Trop. Dis. 2008.V.14, n.4, p. 725-737

13. 12. MEIER J., WHITE JI. Clinical toxicology of animal venoms and poisons. Boca Raton, Florida: CRC Press, 1995. 553-6p.

14. MEIER J., WHITE JI. Clinical toxicology of animal venoms and poisons. Boca Raton, Florida: CRC Press, 1995. 553-6p.

15. MINTON SA. Neurotoxic snake envenoming. Semin. Neurol., 1990, 10, 52-61.

16. WUSTER W., THORPE RS. Asiatic cobras: systematics and snakebite. Cell. Mol. Life Sci., 1991, 47, 205-9.

17. Richard Mastenbroek's Elapid Pages: Kraits (Bungarus ssp.)

18. Living in Indonesia:Banded Krait

19. http://drdavidson.ucsd.edu/Portals/0/snake/ Bungarus.htm "Medical Management for bites by Kraits (Bungarus species)"].

20. Prof Tan, Nget Hong. [monovalent B.fasciatus antivenom "Antivenoms against Malaysian poisonous snakes”]. University of Malaya. Retrieved 2009-09-23. 